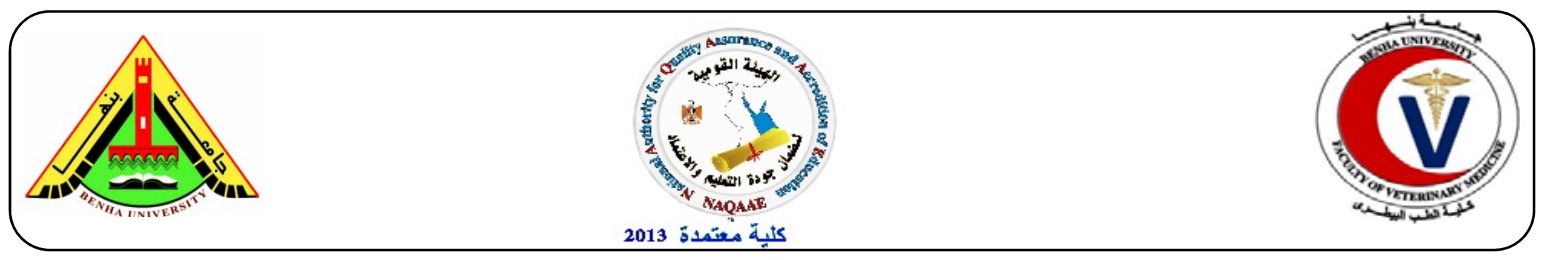

\title{
Rapid tests for detection of enrofloxacin residues in liquid milk
}

\author{
Hamdi A. Mohammed ${ }^{1}$, Adham M. Abdou' ${ }^{1}$, Amal M. Eid ${ }^{2}$, Asem M. Zakaria ${ }^{3}$ \\ ${ }^{1}$ Department of Food Control, Faculty of Veterinary Medicine, Benha University. ${ }^{2}$ Animal Health \\ Research Institute, Tanta Branch. ${ }^{3}$ Department of Food Control, Faculty of Veterinary Medicine, \\ Aswan University.
}

\begin{abstract}
A B S T R A C T
A total of 234 randomly selected milk samples from different sources (110, 50, 34 and 40 samples) from each of (market milk, collecting centers, bulk tank and UHT milk samples; respectively) were analyzed for detection the quinolones residues by rapid quinolones detection strip test. Results revealed that $17.3 \%, 14 \%$ and $20.6 \%$ of milk samples were positive for the quinolones residues for market milk, collecting centers and bulk tank milk samples; respectively, while not detected in UHT milk samples. The positive milk samples were subjected to HPLC analysis for quantitative detection of enrofloxacin residues, which were not detected in market milk and collecting centers milk samples while detected in one sample from bulk tank milk samples. The mean value of $2.94 \mathrm{ppb}$ that not exceeded the maximum residual limit set by different international standards. Public health importance of enrofloxacin residues was discussed.
\end{abstract}

Keywords: Rapid tests, Enrofloxacin, Liquid milk.

(http://www.bvmj.bu.edu.eg)

(BVMJ-30(1): 97-103, 2016)

\section{INTRODUCTION}

$\mathrm{E}$ nrofloxacin is a second generation of fluoroquinolone and is considered to be an ideal antimicrobial preparation because of their strength and width of antimicrobial spectrum of activity so is widely used for animal treatment (Giguère et al., 2007). Milk and dairy products are important nutrients for all age. However, the use of antibiotics for the treatment of dairy animals generates the risk to human health, as these compounds and their metabolites can be transferred to milk (Sanz et al., 2015). The presence of fluoroquinolone residues in milk has attracted extensive attention from public health agencies. This is because of the risks associated with the consumption of food contaminated with fluoroquinolone residues as they may be directly toxic or act as a source of resistant human pathogens, representing a possible health (Juan-García et al., 2006).
Probably the most important threat to human health as a result of fluoroquinolone use in animal production is the development of fluoroquinolone-resistant bacteria. It has been discovered that a major route of transmission of resistant micro-organisms from animals to humans is through the food chain (Hernández-Serrano, 2005). Rapid testing of the presence of antibiotics in milk to grant its quality has become a major task for farmers and dairy industry. The conventional analytical methods are either extending more time or do not enable quantitative detection of antibiotic residues, so alternative methods that are rapid, cost effective and easy to perform should be considered (Kivirand et al., 2015). Colloidal gold immune-chromatographic test strip has been used to detect a variety of antibiotics residues in milk as it's one of the most developed methods for food safety (Gao et al., 2014). A post-screening step for 
positive screening samples must be confirmed, generally with quantitative chromatographic methods (Sanz et al., 2015). Liquid chromatography (LC) is the most sensitive and specific analytical techniques used for the identification and quantitation of antibiotic residues in milk (Navratilova et al, 2011).

Therefore, the present study gives an overview on the recent rapid technique used for the detection of enrofloxacin residues in milk samples then ensuring the results quantitatively by using HPLC and compared the result with the maximum residual limit set by different international standards.

\section{MATERIAL AND METHODS}

\subsection{Samples}

A total of 234 randomly selected milk samples obtained from different sources $110,50,34$ and 40 samples from each of market milk, collecting centers, bulk tank and UHT milk; respectively to estimate the presence of enrofloxacin residues. The samples were collected individually (500 $\mathrm{ml}$ of each) in screw-capped bottles, then were transferred to laboratory in ice box within $1 \mathrm{hr}$ and stored at refrigerator till to be examined.

\subsection{Qualitative detection of quinolones residues in milk samples}

It was carried out by rapid quinolones detection strip test (Nadezhda et al., 2014). Kit contain 100 quinolones rapid test strips, pipettes and quinolones diluent were purchased from Shenzhen Lvshiyuan Biotechnology Co., Ltd D Building, National Biological Industrial Park of Marinelife, No.2 Binhai Road, Dapeng, Shenzhen, 518120 China. The test based on immuno-chromatographic technology. The test has been applied according to the manufacturer instructions. Quinolones in sample in the process of flow combine with the colloidal gold-labeled monoclonal antibody inhibits the antibody combining with quinolone - conjugate binding present in the $\mathrm{T}$ line on the test strip. If the content of quinolone in the sample is high, $\mathrm{T}$ line is lighter than $\mathrm{C}$ line or $\mathrm{T}$ line is invisible.

\subsection{Quantitative detection of enrofloxacin residues in milk samples}

It was carried out by HPLC (Verdon et al., 2004). The milk samples have been examined for the presence of enrofloxacin by a quantitative method as previously described by Verdon et al. (2004). HPLC type: High performance liquid chromatography Agilent series 1050 quaternary gradient pump, Series 1050 auto sampler, series $1050 \mathrm{UV} / \mathrm{Vis}$ detector, and HPLC 2D chemstation software (HewlettPackard, Les Ulis, Germany). The chromatographic column was a reversedphase column (Extend-c18, Zorbax column $4.6 \mathrm{~mm}$ i.d, $250 \mathrm{~mm}, 5 \mu \mathrm{m}$, Agilent Co). HPLC condition: Injection volume $20 \mu$, flow rate $1 \mathrm{ml} / \mathrm{min}$, column temperature $50^{\circ} \mathrm{C}$. UV- detector wave length: $280 \mathrm{~nm}$ and the mobile phase: acetic acid $(50 \mathrm{~mL} / \mathrm{L}$ distilled water): acetonitril: methanol (900: 50: 50). Samples preparation: $2 \mathrm{ml}$ of milk sample were added to $8 \mathrm{ml}$ of $5 \%$ Trichloro acetic acid (TCA) then mixing by Vortexmix for $1 \mathrm{~min}$ after that we make rotary agitate for 10 mints followed by centrifugation for 5 mints $(14000 \mathrm{rpm}$ $+4^{\circ} \mathrm{C}$ ) then Filtrate supernatant on $0.45 \mu \mathrm{m}$ nylon filter and $20 \mu \mathrm{l}$ were injected into the LC instrument (liquid/liquid extraction method). Stock standard solution of enrofloxacin were prepared at concentration of $(10,50$ and1000) ppb. The calibration curves were generated and quantification of residues in the sample was obtained and calculated from area under curves extrapolated automatically by the software.

\section{RESULTS}

Table (1) showed that $17.3 \%, 14 \%$ and $20.6 \%$ of milk samples were positive for the presence of quinolones residues for market milk, collecting centers and bulk tank milk samples; respectively, while not detected in UHT milk samples. The statistical analysis revealed that the difference between the 
percentages of quinolones residues present in the milk samples from different sources was significant $(P=0.034)$. Table (2) showed that enrofloxacin residues were not detected in market milk and collecting centers milk samples while detected in one sample from bulk tank milk samples with a mean value of $2.94 \mathrm{ppb}$. The statistical analysis revealed that the difference between the mean values of enrofloxacin residues in milk samples were nonsignificant $(P=0.094)$. Table (3) showed that positive milk sample had enrofloxacin residue concentration not exceeded maximum residual limits set by different international standards.

Table (1): Statistical analytical results of rapid quinolones detection strip test

\begin{tabular}{lccccc}
\hline Quinolones residues & Market milk & $\begin{array}{c}\text { Milk collecting } \\
\text { centers }\end{array}$ & Bulk tank & UHT milk & P - value \\
\hline Examined samples & 110 & 50 & 34 & 40 & \\
No of + ve & 19 & 7 & 7 & 0 & \\
$\%$ of + ve & 17.3 & 14 & 20.6 & 0 & 0.034 \\
\hline
\end{tabular}

Table (2): Descriptive statistical results of enrofloxacin residues in examined milk samples measured by HPLC

\begin{tabular}{lcccc}
\hline Quinolones residues & Market milk & $\begin{array}{c}\text { Milk samples } \\
\text { Milk collecting } \\
\text { centers }\end{array}$ & Bulk tank & P - value \\
\hline Examined samples & 110 & 50 & 34 & \\
No of +ve & 0 & 0 & 1 & \\
\% of +ve & 0 & 0 & 2.9 & 0.094 \\
Concentration $(\mathrm{ppb})$ & 0 & 0 & 2.94 & \\
\hline
\end{tabular}

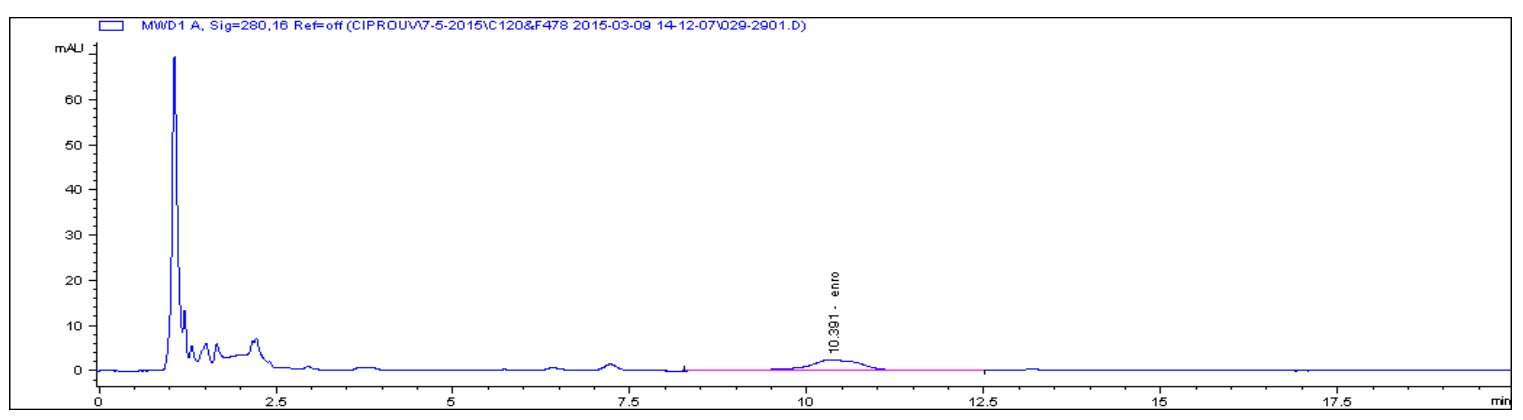

HPLC curve for enrofloxacin concentration in +ve bulk tank milk sample (2.94 ppb).

Table (3): Interpretation of the enrofloxacin residues in the examined samples with the international standards of permissible enrofloxacin residues limits

\begin{tabular}{lccc}
\hline $\begin{array}{l}\text { Enrofloxacin residues } \\
(\mathrm{ppb})\end{array}$ & $\begin{array}{c}\text { EU* } \\
(100 \mathrm{ppb})\end{array}$ & $\begin{array}{c}\mathrm{CR} * * \\
(50 \mathrm{ppb})\end{array}$ & $\begin{array}{c}\text { JFCRF*** } \\
(50 \mathrm{ppb})\end{array}$ \\
\hline Bulk tank milk (2.94) & Acceptable & Acceptable & Acceptable \\
\hline *EU: European Commission (2010), **CR: China regulation of Anon, GB 29692-2013 (Rong-jie et al., 2014), \\
***JFCRF: Japan Food Chemical Research Foundation (Change et al., 2010).
\end{tabular}




\section{DISCUSSION}

Enrofloxacin is a second generation fluoroquinolone with bactericidal activity approved for use as a veterinary drug and when it is metabolized, its pharmacologically active metabolite, ciprofloxacin, is produced (Navrátilová et al., 2011). Several reports have been shown that the presence of fluoroquinolone residues in human food obtained from animal sources has reduced the use of these agents in human medicine. In addition to the direct toxicity and other side effects of fluoroquinolones are well established in animals and humans (Gruchalla and Pirmohamed, 2006; Khadra et al., 2012). Thus it is important to monitor the residues of fluoroquinolone in frequently consumed milk. Efficient monitoring of fluoroquinolone residues would require screening tests which give rapid results, expected to be simple, cheap, and easy to perform and allow simultaneous analysis of large number of samples (Sanz et al., 2015). Rapid quinolones detection strip test kits is rapid (10 $\mathrm{min})$, relatively simple and easy to use (Cheng et al., 2014). The percentages of presence of quinolones residues in the examined milk samples were ranged between 14 and 20.6\% (Table 1). Higher results were reported by Navratilova et al. (2011) whom recorded that $87.3 \%$ of the raw milk samples were positive for the quinolones residues. While lower results were reported by Aguilera-Luiz et al. (2008) and Nizamlığlu and Aydın (2012) whom recorded that none of the examined raw milk samples were found to be positive for quinolone residues. Presence of quinolones residues in milk may be attributed to that quinolones entered the food chain either by illegal use or by non-compliance of producers to existing animal treatment protocols (withdrawal times) prior to milking (Sats et al., 2014). In contrary, absence of quinolones residues in UHT milk may be due to selection and regular monitoring of milk for presence of antimicrobial residues before processing. Factories of dairy products usually use Hazard Analysis and Critical Control Point (HACCP) system in their production plan. The HACCP system approached to minimize economic losses and food poisoning outbreaks from all steps in the dairy production process (Peristeropoulou et al., 2015). Heat treatment may have minor role in reduction of quinolones residues in milk (Roca et al., 2010). Findings in this study revealed that quinolones are frequently administered in dairy animal production, so regular monitoring of these residues in milk must be done. The lack of volatility and thermal instability of many antibiotics make HPLC the best of choice for analysis and confirmation of veterinary drug residues (Kennedy et al., 1998).

Reviewing the data in Table (2) showed that the percentages of enrofloxacin residues in the examined milk samples were ranged from 0 to 2.9 with mean value of $2.94 \mathrm{ppb}$ for the examined bulk tank milk samples. This means that there was no statistical significant difference as regard the percentage of enrofloxacin residues in milk samples $(P=0.094)$. Nearly similar percentages were reported by Bilandžić et al. (2011) whom detected enrofloxacin residues in a percentage of 4.11 in raw milk samples. While the higher percentage were reported by Moharana et al. (2015) and Navratilova et al. (2011) Whom detected enrofloxacin residues with a percentage of 16.8 and 87.3 ; respectively in the examined raw milk samples.

Enrofloxacin is the most effective fluoroquinolone and is often prescribed for the animals treatment so its presence as a residue in milk is predicted but its presence in low percentage may be due to that enrofloxacin was extensively metabolized to ciprofloxacin, and the tissue metabolite concentrations were always equivalent to or higher than those of the parent compound (Anadon et al., 1995) also compliance of 
producers to existing animal-treatment protocols (withdrawal times) may reduce the incidence of its presence in milk. In the current study, it is pointed out that none of positive milk samples has enrofloxacin residues concentration exceeded the maximum residual limits (MRLs) set by different international standards like EU (European Commission 2010), China regulations (Rong-jie et al., 2014) and Japan Food Chemical Research Foundation (Change et al., 2010). Same results were set by Bilandžić et al. (2011) and Navratilova et al. (2011). While, higher results were reported by Moharana et al. (2015). Low concentration of enrofloxacin residues in milk may be attributed to compliance of producers to existing animal-treatment protocols (withdrawal times) prior to milking treated animals (Sats et al., 2014) or high dilution of enrofloxacin residues contaminated milk by enrofloxacin residue free milk may reduce enrofloxacin residues in the examined milk samples. The most important side effects of fluoroquinolone include renal impairment, ocular disorders and damage the articular cartilage. Other adverse effects include, e.g., frequent gastrointestinal disturbances (diminished appetite, nausea, abdominal pain, vomiting and diarrhea), headache, insomnia, tension, or skin allergy manifestations and drug resistance (Flomenbaum et al., 2006). There is no doubt that neither humans nor animals can live without antibiotics as they are some of the most effective antimicrobial treatments. But the misuse of antibiotics may result in the aforementioned health hazards. Thus, the reduction of antibiotic use constitutes a challenge for the world (Darwish et al., 2013).

\section{REFERENCES}

Aguilera-Luiz, M.M., Vidal, J.L., Gonz, R.R., Frenich, A.G. 2008. Multiresidue determination of veterinary drugs in milk by ultra-high-pressure liquid chromatography-tandem mass spectrometry. J. of Chromatography A, 1205: $10-16$.

Anadon, A., Martinez-Larranaga, M.R., Diaz, J., Bringas, P., Martinez, M.A., Fernandez-Cruz, M.L., Fernandez, R. 1995. Pharmacokinetics and residues of enrofloxacin in chicken. American .J .of Vet. Res., 56 (4) : 501- 506.

Bilandžić, N., Kolanović, B.S., Varenina, I., Jurković, Z. 2011. Concentrations of veterinary drug residues in milk from individual farms in Croatia. J. Mljekarstvo, 61 (3): 260 - 267.

Change, C., Wang, W., Entasin, C. 2010. Simultaneous determination of 18 Quinolone Residues in Marine and Livestock Products by Liquid Chromatography/ Tandem Mass Spectrometry. J. Food and Drug Analysis 18(2): 87-97.

Cheng, N., Zhu, L., Xu, Y., Xu, W. 2014. A Review of Test Strips in Rapid Detection of Food Safety. Austin J. Nutri Food Sci., 2 (7): 1038.

Darwish, W.S., Elsaid, A., El-Abbasy, M.T., Yoshinori Ikenaka, Y., Nakayama, S., Ishizuka, M. 2013. Antibiotic residues in food: the African scenario Japanese. J. of Vet. Res., (61): 13- 22.

European Commission. 2010. Commission Regulation (EU) No. 37/2010 of 22 312 December 2009: on pharmacologically active substances and their classification regarding maximum residue limits in foodstuffs of animal origin. 313 Official Journal 314 of the European Union, L15, 172.

Flomenbaum, N.E., Goldfrank, L.R., Hoffman, R.S., Howland, M.A., Lewin, N.A., Nelson, L.S. 2006. GoldfranksToxicologic Emergencies. 8th Ed. McGraw-Hill, New York.

Gao, H., Han, J., Yang, S., Wang, Z., Wang, L., Fu, Z. 2014. Highly sensitive multianalyte immunochromatographic test strip for rapid chemiluminescent detection of 
ractopamine and salbutamol. J. Anal Chim Acta; 839: 91-96.

Giguère, S.J., Prescott, F., Baggot, D., Walk, R.D., Dowling, P.M. 2007. Antimicrobial Therapy in Veterinary Medicine, 4th Edition, ISBN: 978-08138-0656, Blackwell Publishing, UK.

Gruchalla, R.S., Pirmohamed, M. 2006. Antibiotic allergy. The New England J. of Med. 354, 601-609.

Hernández Serrano, P. 2005. Responsible Use of Antibiotics in Aquaculture. FAO Fisheries Technical Paper. 469497.

Hussein, M.A., Khalil, S. 2013. Screening of Some Antibiotics and Anabolic Steroids Residues in Broiler Fillet Marketed in El-Sharkia Governorate. Life Sci. J., 10 (1).

Juan-García, A., Font, G., Picó, Y. 2006. Determination of quinolone residues in chicken and fish by capillary electrophoresis-mass spectrometry. Electrophoresis. 27, 2240-2249.

Kennedy, D.G., McCracken, R.J., Cannavan, A., Hewitt, S.A. 1998. Use of liquid chromatography-mass spectrometry in the analysis of residues of antibiotics in meat and milk. Journal of Chromatography, A 1067: 93 - 100

Khadra, A., Pinelli, E., Lacroix, M.Z., Bousquet-Melou, A., Hamdi, H., Merlina, G., Guiresse, M., Hafidi, M. 2012. Assessment of the genotoxicity of quinolone and fluoroquinolones contaminated soil with the Viciafaba micronucleus test. J. of Ecotoxicol., and Environ., Saf., 76, 187-192.

Kivirand, K., Kagan, M., Rinken, T. 2015. Biosensors for the Detection of Antibiotic Residues in Milk. Institute of Chemistry, University of Tartu, Tartu, Estonia. http://dx.doi.org /10.5772/60464. kairi. kivirand @ut.ee.

Moharana, B., KarthickVenkatesh, P., Preetha, S.P., Selvasubramani- an, S. 2015. Quantification of enrofloxacin residues in milk samples using RPHPLC. World J. of Pharmacy and Pharmaceutical Sci., 4: (10) 14431450.

Nadezhda, A., Nataliya, I., Anatoly, V., Sergei, A., Ilya, A., Yuanming, S., Boris, B. 2014. Rapid immunochromatographic assay for ofloxacin in animal original foodstuffs using native antisera labeled by colloidal gold . Talanta. 119 (125-132).

Navratilova, P., Borkovcova, I., Vyhnalkova, J., Vorlova, L. 2011. Fluoroquinolone residues in raw cow's milk. Czech J. Food Sci, (29): 641- 646 .

Nizamlığlu, F.O., Aydın, H. 2012. Quinolone antibiotic residues in raw milk and chicken liver in Konya Eurasian. J. Vet Sci 28, 3, 154-158.

Peristeropoulou, M., Fragkaki, A.G., Printzos, N., Laina, I. 2015. Implementation of the Hazard Analysis Critical Control Point (HACCP) System to a Dairy Industry: Evaluation of Benefits and Barriers. J. Food Nutri Diete 1(1): 102.

Roca, M., Castillo, M., Marti, P., Althaus, R.L., Molina, M.P. 2010. the effect milk processing temperatures on the presence of antimicrobial residues. J. Agric Food Chem. 58(9):5427-31.

Rong-jie, F.u., Sun, J.L, Yun-qing, L.I. 2014. Agilent Technologies Shanghai Co. Ltd Analyze Quinolone Residues in Milk with an Agilent Poroshell 120, $4 \mu \mathrm{m}$ Column. www. agilent.com/chem.

Sanz, D., Razquin, P., Condón, S., Juan, T., Herraiz, B., Mata, L. 2015. Incidence of Antimicrobial Residues in Meat Using a Broad Spectrum Screening Strategy. European J. of Nut., \& Food Saf., 5(3): 156-165.

Sats, A., Mootse, H., Lepasalu, L., Poikalainen, V. 2014. Use of Delvotest $\mathrm{T}$ for Quantitative Estimation of $\beta$-lactam Antibiotic Residues in Waste Milk and for 
Evaluation of Thermal Treatment Efficiency - a Methodical Pilot Study Agronomy Research 12(3): 807-812.

Verdon, E., Couëdor, P., Sanders, P., Afssa-Lermvd. 2004. Validation of a multi- quinolones, multi-matrix, multi-species method for the determination of quinolones residues by HPLC with fluorescence detectin. French Agency for Food Safety, BP 90203, 35302 Fougères, France. 